\title{
Hermeneutic Notion of a Human Being as an Acting and Suffering Person: Thinking with Paul Ricoeur
}

\author{
Andrew Wiercinski (University of Freiburg)
}

\section{A Human Being as a Narrative Identity}

Paul Ricoeur's poetics of narrative is a response to the aporias of temporality: "Time becomes human time to the extent that it is organized after the manner of a narrative; narrative, in turn, is meaningful to the extent that it portrays the features of temporal experience" [Ricoeur 1984, 3] ${ }^{1}$. In his long and passionate journey through historical and fictional narrative, Ricoeur discovers that narrative identity fuses and integrates those two narratives. We do not have direct access to our self-understanding, but are not left alone in searching for meaning of our lives. In signs and symbols, we are offered a privileged mediation, which equally draws on history as on fiction. We arrive at selfknowledge through interpretation and our self-interpretation finds its realization (Vollzug) in the narrative. In this undertaking we search for understanding of what does it mean to be a human being as an individual and a member of a community.

\section{"Who Acts and Suffers?" and "Who Tells the Story of Facing Life?"}

In the conclusion of Time and Narrative, Ricoeur introduces the notion of narrative identity as a process of the interweaving of history and fiction:

The fragile offshoot issuing from the union of history and fiction is the assignment to an individual or a community of a specific identity that we can call their narrative identity...To state the identity of an individual or a community is to answer the question, "Who did this?" "Who is the agent, the author?"...The answer has to be narrative. To answer the question "Who?" as Hannah Arendt has so forcefully put it, is to tell the story of a life. The story told tells about the action of the "who." And the identity of this "who" therefore itself must be a narrative identity. Without the recourse to narration, the problem of personal identity would

\footnotetext{
${ }^{1}$ I would like to thank Dr. Daniel J. Shuster for his very careful reading of my paper and his invaluable comments and editorial suggestions.
} 
be in fact condemned to an antinomy with no solution. [Ricoeur 1988, 246; also: Hengel 2002, 124]

Narrative identity is an individual internalized and evolving life story. The factual experiences are recreated in memories and interpretations of those experiences. They integrate the reconstructed past and imagined future. Being recombined forward over time, and reinterpreted in light of each new unfolding experience, and the shifting social and material circumstances unique to each of us they build a basis for the formation of personal identity. The narrative alone can define the "who" and as the narrative changes, as does the identity, and the story of a life is always a mutable snapshot in time. For the "who" of writers, the narrative is carried forward by others as the writer's work is continually reinterpreted in time and culture. The exigent moment we are in today calls for interpreting the notion of narrative identity in direct response to contemporary time and culture. Our ideas get cross fertilized with each other's life experience; as well as all of that interpretation through the intervening historical and social changes that have transpired. This is how humanity evolves hermeneutically.

Narrative identity attempts to capture the existential experience of an individual in the story of one's life. It embraces the whole of human life without fixing it into a static paradigm. On the contrary, it consents to mutability in life, or even further, it welcomes challenges and changes as indispensable to live a constructive and creative life with integrity and cohesion of the individual life as a project for which we are solely responsible: "The story of a life continues to be refigured by all the truthful or fictive stories a subject tells about himself or herself. This refiguration makes this life itself a cloth woven of stories told" [Ricoeur 1988, 246]. Ricoeur introduces here a metaphor of life as a cloth, which comes from Joseph Roth's Novel "April." We can add that this cloth is a cloth woven with pain. It is pain, which makes this cloth woven of stories told into a human life; pain of telling the story of our life, pain of not being able to give an adequate testimony to life, to what André Malraux calls "la condition humaine" [Malraux 1933]. There is also a joy of the human condition, which tints this cloth of happiness and sorrow with a joy of accepting and enduring life. As humans, we are called to wear this cloth; a cloth woven with countless separate stories told throughout our life and the history of mankind. Along with the weaving of history with fiction, the "woven" cloth is a continuous "weaving" of our identity with each new horizon we encounter; traveling and morphing like a shadow before us. Since the narrative of one's life is continuously "refigured," the notion of "a" cloth needs to be seen as a moment-to-moment interactive hermeneutic weaving with the joys and pains of our daily experience. For the sake of a germane mutuality, the harsh reality of our time needs to be critically and dialectically engaged with our evolving ontologies and epistemologies. The sense of the self is transformed every time based on our reflective engagement with the world. 
Telling our life story, each time we see ourselves in a dynamic tension between the intervening experience of joy, pain, and people and our conscious, dialogic engagement with them.

The dynamic aspect of narrative identity emphasizes the essential incompleteness of telling the story of one's life. There is always more to be told and only in telling the story we recognize the complexity of this project. Facing the limits of language in which we tell our stories, we realize that each story of a life as such, no matter how extensive and comprehensive, is not exhaustive. It is only provisional not because of any particular deficiency, but because it is the story of a human life, which is by nature historical, lingual, and finite; and this story is told by someone who is a historical, lingual, and finite human being. On the one hand, we have a cognitive ambition and a desire to give our own testimony to the ultimate quest for the meanings of many things happing in our life at once. On the other hand, we cannot but suffer with a poet painfully experiencing that "reflections of clouds and trees are not clouds and trees" [Miłosz 1988a, 221].

Nevertheless, we want to convey the life's story because we feel that we have to give a testimony about the way we cope with life's demands. We are painfully aware that there are those who have something important to share and do not speak, but even more hurting and disturbing is awareness that there are those who speak and do not want to share life but simply repeat something what they apparently know and wish to disclose. In every story telling, we face a fundamental tension between the conviction that there is something about what we have experienced and witnessed in our life that we want to convey and the uncertainty about how to express this witness to others. It is precisely this uncertainty that calls for the scrutiny of our life, our motifs, and intensions, even if this appears to bring us no tangible and immediate benefits. This uncertainty serves also as an open invitation for relentless search for a more spacious form of telling the life's story. Like in this compelling testimony about the personal and artistic search in a life of the poet:
No More
I should relate sometime how I changed
My views on poetry, and how it came to be
That I consider myself today one of the many
Merchants and artisans of Old Japan,
Who arranged verses about cherry blossoms,
Chrysanthemums and the full moon.
If only I could describe the courtesans of Venice As in a loggia they teased a peacock with a twig, And out of brocade, the pearls of their belt, Set free heavy breasts and the reddish weal Where the buttoned dress marked the belly, 
As vividly as seen by the skipper of galleons

Who landed that morning with a cargo of gold;

And if I could find for their miserable bones

In a graveyard whose gates are licked by greasy water

A word more enduring than their last-used comb

That in the rot under tombstones, alone, awaits the light,

Then I wouldn't doubt. Out of reluctant matter

What can be gathered? Nothing, beauty at best.

And so, cherry blossoms must suffice for us

And chrysanthemums and the full moon [Miłosz 1988b, 123].

The desire to be as accurate to a concrete human person and experience as possible is accompanied by a despair of a poet who knows that one can, and, in fact, should be genuinely disturbed by the inadequacy of our human endeavors. Therefore, we cannot stop doubting in our capability to preserve everything precious what should be preserved in our individual and collective memory. But this distrust does not prevent us from trying even harder. Searching for a more fitting expression happens on a pathway of a conversation with oneself and the other. The constrains of the form mark moments of discouragement and disheartenment, but they also increase a hope in a word more enduring and able to break down the barriers caused by obstinacy in recognizing the power of memory, forgiving, and forgetting. A chief task of telling the life's story is to display the essential vulnerability of human life and its indispensability for understanding the self and the other.

At first glance, it might seem that there is a contradiction between the poet's complaint about the impossibility of expressing the whole of the beauty of the world ("If only I could describe the courtesans of Venice") and what is actually happening in the poem. Giving the vivid description of the courtesans, the poet confirms the futility of the poetic endeavor to capture the world in words. And yet, we meet in a poem a human being embodied in a life's story well told by the poet. By examining, confronting, and embracing inter-human entanglement, the poet testifies to the glory of an individual human being just because one lives in this world and is intersubjectively transformed or found or reified by it through communication with others.

As the storytellers we are confronted with the question "What to convey in telling the life's story," and "Who wants to know our life's story?" Even more fundamental is the conviction that our own life story needs to be told and valued as an unrepeatable story, because every life is an unrepeatable experience. In his essay "Life in Quest of Narrative" [Ricoeur 2002] Ricoeur elevates storytelling to the privileged modus of understanding ourselves and making meaning out of our lives. The importance of storytelling, even to ourselves, cannot be overlooked. In fact, life can be understood as a story in search of a narrator. Narrating our life story, we turn it into a work of art. Narrating life as an artistic endeavor has a clear ethical dimension. For 
Ricoeur, art "constitutes so many thought experiments by which we learn to link together the ethical aspects of human conduct and happiness and misfortune" [Ricoeur 2002, 23]. Storytelling as an exercise in situating ourselves between happiness and misfortune is an invaluable lesson and a crucial experience toward the phronetic understanding of life in all its dimensions.

In Oneself as Another, Ricoeur emphasizes the role of narrative identity in the constitution of the self [Ricoeur 1992]. Addressing the challenges of personal identity in the fifth study, Ricoeur distinguishes between two aspects of personal identity, sameness (mêmeté) and selfhood (ipséité). Sameness (mêmeté, idem) expresses the fact that a person remains the same regardless the changes one is undergoing. The self can identify the self as self despite the changes the self undergoes in time. As a numerical identity, sameness is a qualitative identity, which happens between a thing and itself. This qualitative identity is an absolute identity; therefore, different occurrences of something are, in fact, the same thing. Ricoeur calls also this numerical identity an uninterrupted continuity. For him, there are four different senses of sameness and their opposites. He relates them to the concept of identification: Uniqueness versus plurality; resemblance versus difference; continuity versus discontinuity; permanence versus diversity [see: Hamilton 2013, 74].

Selfhood (ipséité, ipse) articulates a relationship one has to oneself. It is a manifestation of our individuality, which stresses the uniqueness of every human being. Selfhood refers to those inexpressible aspects of our life that characterize us as what we really are. It is an expression of a relational nature of a human person as described by Richard of Saint Viktor: Persona est naturae intellectualis exsistentia incommunicabilis. The ipse identity is the identity which belongs to an individual self, and as such it is distinctly different from the identity belonging to another person. Selfhood denotes the identity which belongs to oneself and not to the other individual. However, this another can be oneself. Therefore, the ipse identity designates the identity which belongs to oneself as another. Oneself as another is, in fact, a mode of being oneself. Ipse identifies "who" the self is, idem "what" the self consists of.

Ricoeur chooses two models of permanence in time - character and keeping one's word - as examples which disclose the specificity of idem and ipse identity. While the permanence of character "expresses the almost complete mutual overlapping of the problematic of idem and of ipse," "faithfulness to oneself in keeping one's word marks the extreme gap between the permanence of the self and that of the same" [Ricoeur 1992, 118]. In a creative tension between those two models, "an interval of sense" is formed "which remains to be filled in" [Ricoeur 1992, 124]. Ricoeur's continuous interest in the notion of narrative identity allows him to change the perspective from which he addresses the task of personal identity formation. Moving from relating narrative identity to time in Time and Narrative, Ricoeur 
concentrates on the indispensability of narrative identity to the constitution of the self in Oneself as Another. As l'homme capable we not only have our history, but we our history. What is at stake here is the mediation between temporality in the sense of changes we undergo in life and personal identity in the sense of permanence in time.

The confrontation of those two expressions of personal identity discloses the tension between more stable and permanent components of the self, related to idem (identity as sameness) and the evolving, shifting, and dynamic aspects of the self, related to ipse (identity as selfhood). Narrative identity mediates this confrontation. It occurs "in the manner of a specific mediator between the pole of character, where idem and ipse tend to coincide, and the pole of self-maintenance, where selfhood frees itself from sameness" [Ricoeur 1992, 119].

The tension between idem and ipse identity discloses an important aspect regarding the relationship between the self and the other. According to Ricoeur, the self implies a relation between the same and the other, therefore, selfhood and otherness cannot be separated. Ricoeur's dialectics of the self and other perceives a human person always in relationship to the other. This is the fundamental divergence from Descartes' cogito ergo sum, je pense donc je suis, which posits a subject in the first person and emphasizes the indubitability of first-person experience without reference to the other. Such is the direction the Enlightenment has taken us - away from mutuality and the spirit that joins us - to the present Western neoliberal corporatist culture that strips away spirit, authentic relationship, dialogue, dissent, and community.

\section{A Human Person as l'homme capable and l'homme agissant}

For Ricoeur, l'homme capable and l'homme agissant are synonyms. A notion of a human being as a capable person emphasizes the potential of identifying oneself by the capacities, which embrace everything one can do. Those capacities are inherently connected with the vulnerability of the human condition, and only together can coherently describe a human person as an acting and suffering human being. Facing our vulnerability, fallibility, and culpability, we have the potential of experiencing our capacities and vulnerabilities in the mode of certainty as an attestation to the self, regarding who we are and what we can do, and how do we suffer. Among the capacities of a capable human being we can lists the basic powers that institute us as human persons: The capacity to speak, which presupposes an expectation of being heard, the capacity to act, to narrate or to tell stories that disclose the hidden possibilities of life, the capacity to be responsible and accountable for our actions, and the capacity to promise. In his late work, particularly in Memory, History, Forgetting, Ricoeur elaborates on the capacity to forgive, which is a powerful potential of addressing a liberating word to the other, and, 
it is not just a sentiment of an old man, the capacity to experience a happy memory, which calls for a responsible balance between remembering and forgetting without ever overcoming the tension [Ricoeur 2004]. As we age, our feelings of insufficiency in everyday life become more and more explicit. What follows, is the increasing difficulty in finding hope in life. All this makes reconciliation with oneself, the other, and finally with life into a substantial project, which very often overburden us. Personal experience is the genesis of true learning. No matter what stage of life we may find ourselves in, reconciliation with life requires patience and discipline. In fact, reconciliation with life becomes a discipline in our incessant striving for the true, the good, and the beautiful in life. The word discipline comes from the Latin disciplina, which means "teaching" and "learning". Everyone is discipulus, a pupil in a school of life. As l'homme capable and l'homme agissant we are learners who want to become capable, engaged, and effective disciples, passionate about life, and love, and being the best we can be. Those who practice the art of listening through mutuality act as powerful accelerants to the blossoming of healthy narrative and assumptive reality.

Ricoeur's l'homme capable indisputably refers, through Gabriel Marcel's influence, to the Christian tradition, which understands a human being as homo capax Dei. This is the privileged position in the universe, which makes a human person able to know and love God. On the other hand, Ricoeur is inspired by the Protestant notion of a human being, especially elaborated by Karl Barth with his formula finitum non capax infiniti, which emphasizes the unbridgeable gap between the finite human being and the infinite God. When Barth was asked about the advantages of studying the Bible, he apparently answered, "Jesus loves me, this I know, for the Bible tells me so." Being finite human beings, we do not have the direct access to God. However, we can witness the promises of God fulfilled in the Word of God and have an intimate

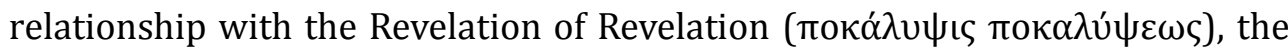
incarnated God in the person of Jesus. He himself indicated clearly that personal identity formation is the process, which happens in a community of disciples. They are the Twelve, and not the One. Each member is called to find one's own identity in Jesus. This identity is further reinforced and strengthened intersubjectively through telling and listening among themselves to testify and convey a consistent narrative to the world beyond their own life times.

\section{Telling Our Individual Stories as Culture Making}

Human life is a process of uncovering our belonging to tradition that we are, and culture. Our task is to reclaim the cultural mandate to be creative cultivators of the world we live in. This creativity we show in everything we make of the world and it is not reserved to the production of cultural artifacts, 
but it involves the whole of human activity and embraces the challenging task of making sense of the world around us. Since Cicero and his Tusculan Disputations, we are cuddly aware of the most important task we have to accomplish in our life, which is also, in turn, the highest possible ideal for human development, which is the cultivation of the soul, cultura animi ${ }^{2}$. Our everyday life and personal creativity are the ways in which we participate in culture making.

One of the primordial expressions of human creativity is walking. The verb walk descends from the Old English "wealcan", "to roll." Another word for walking is "ambulation", from ambulare, to walk from place to place; move about. Walking is one of the simplest expressions of human life perceived as being in motion. To walk is an art; it is a mode of our being in the world. In a worldwide tendency to uniformity, we wish to emphasize the necessity of prodigious diversity, without subordinating to any particular form of life.

The art of walking reminds us that there is a very close relationship between walking and looking. It beautifully summarizes the notion of existentia hermeneutica: Walking and looking always call for interpretation and understanding of where are we going and how we are supposed to endure the fatigue of the journey. Walking is a powerful expression of culture making and discloses the transformative and communal aspect of human life. Walking in community, not only with friends and those who love us, helps us to disclose the meaning of life and the very danger of interfering with and destroying the diversity in the world we live in, which is our world. It is heart wrenching to see the art of walking disappear particularly in North America. The architecture and extreme economics discourage us from walking. We do not have interests or time for it. In our driving around to consume, walking becomes obsolete. After all, why walk when we can be carried anywhere we want to go. Walking changes the horizon. We walk on a round earth with a horizon that recedes at about 14 miles in any direction we take. Driving requires a nearer focal point and occurs at speeds that preclude reflection of new topologies vis-à-vis our pre-constructed ones. Walking around a sculpture gives us a holistic hermeneutics instead of a two-dimensional profile like a Hollywood stage town.

\section{The Windows}

In these dark rooms where I live out empty days, I circle back and forth trying to find the windows.

It will be a great relief when a window opens.

But the windows are not there to be found or at least I cannot find them. And perhaps it is better that I don't find them.

Perhaps the light will prove another tyranny.

2 "Cultura autem animi philosophia est". Cicero Disputationes 2, 13. 
Who knows what new things it will expose? [Cavafy 2002].

Personal identity is expressed and shaped by the narratives. It is like wandering to and fro seeking for a window. This task of seeking discloses personal identity as an unstable equilibrium; it unfolds as the story unfolds [see: Wiercinski 2003]. It is circling back and forth, which calls for the highest concentration of attention to life. It calls for listening to the voice of life. And as such, this is a call for radical responsibility to live our lives to the fullest [Jonas 1984]. No one can answer this call for us. But this call is heard by us in the midst of our everyday life, when we often desperately search for light and fresh air. Our self-understanding is happening always in-between, always walking back and forth, and always searching for something we cannot live without. Paradoxically, our self-understanding develops in a tension between walking on a safe ground and within the limits of our personal security and comfort and walking in the areas of risk. Not understanding this tension will impede us from growing.

There are people who cannot walk. In the Gospel of John 5, Jesus heals a crippled man resigned to his illness. In that healing encounter, Jesus points to two illnesses: The inability to walk and the lack of faith and hope in being cured; a wounded ego losing the courage to stand up and fight for life. This means that a crippled man is double paralyzed, in his body and in his spirit. The spiritual paralysis leaves no space for God to act. Upon seeing the misery of a crippled man and facing him as a double wounded self, Jesus only asks if he wishes to be healed. And the man being cured at once picks up his mat and starts to walk around. It is a powerful story about losing hope and being healed and a more general lesson about wanting to be healed and wanting to be well again, and how one comes to it and receives the gift of healing. The gift economy does not offer us any measures for our gratitude. However, it creates an obligation to use wisely the gift we have received and to remain open. Walking again is a sign of openness, of this new beginning of an ongoing process of uncovering, and letting go of the ways in which we have been closed to life. Christ's admonition "do not sin any more" can be read not only as a call for personal conversion, $\mu \varepsilon \tau \alpha \dot{\alpha} v o t \alpha$, a transformative change of heart, but as an invitation to be a gift to others, to pass on the encouragement for living life despite tribulations, hardships, and weaknesses.

Anyone who has difficulty walking can testify to the double paralysis and no space for God to act. Being in John's dark night of the soul, one can painfully experience the pressure of being the "Other." There certainly is a closedness that comes with the social stigma associated with the lame which requires constant effort to overcome. However, what is amazing is the possibility of influencing people around us by inviting them to see differently and arrive to a different understanding of disability as not a simple inability to walk but as an invitation to face oneself in truth about one's own being and 
manage life in constructive ways, despite unavoidable disappointments, bitterness, and frustrations.

Sometimes we might have to go through different disabilities just to recognize the need to pause in order to realize the overwhelming sense of utter powerlessness in the face of an inescapable pain and suffering in life. We might walk but as a dead body, closed to life. The miracle of waking again is not only a manifestation of the divine power, but an offer to pursue a new direction in life. It is an invitation for a transformative process in which we uncover the meaning of our life; an invitation to persist and persevere in the growth in openness and to resist the existence closed in fear and in a tight circle of impossible expectations for life resulting in existential failure. Not walking cloisters you from the life world.

This biblical encounter is a resounding yes to life. Walking again means re-orienting, re-directing oneself, and re-locating. It is an opening of a new horizon for a new life. Nothing will be the same. It will be decisively a new life with the restored capacities. This new experience of being well again is much more complex that the ability to walk. It is a different kind of walking, walking in the faith that there is no human despair which can have the last word over us. Being crippled is not a final word for life. Jesus's admonition "don't sin anymore" (John 8, 11?) is a call for having trust in life regardless of hardships and tribulations, a willingness to do something radical about one's life at every moment.

As Hans-Georg Gadamer reminds us, we understand always differently when we understand at all: "It is enough to say that we understand in a different way, if we understand at all" [Gadamer 2004, 296]. Our selfunderstanding is not static, but is a work in progress. We cannot overlook the realities of everyday life. Only in keeping with our needs and those of people around us (Mit-sein), the needs of the place and of the times, we can search for a possible relief, but also allow for fears to find the ways to express themselves. Hermeneutically speaking, there is no voice which can be suffocated if we want to live a human life. It is important never to be at peace with conventional answers but always patiently learn to listen to the voices, which often bring about the great confusion rather than simple clarity. This surrendering to the voices of human life without manipulating them uncovers the potential of being different. It is an answer to the transformative call of Being, which requests our re-positioning in life, our con-versio.

\section{Hermeneutic Hospitality: Indispensable Openness To Our Self-understanding Calls for Welcoming and Responsible Openness for the Alterity of the Other}

Understanding ourselves highlights the centrality of the openness we practice with relationship to ourselves and to others. This openness is not just 
a hermeneutic postulate, but is an existential requirement, which becomes the way in which we live our life. It shows itself in our story-telling, when we face the stories of invisibility and concealment, but also get scared of the potential violence of disclosure. Telling the story we wish to get into the essence of our life, realizing all the traumas of disembodiment we experience in narrating ourselves, without attempting to overcome change and mutability in favor of continuity and integrity. Faithfulness to oneself in keeping one's word "does indeed appear to stand as a challenge to time, a denial of change: Even if my desire were to change, even if I were to change my opinion or my inclination, 'I will hold firm'"' [Ricoeur 1992, 124].

Facing life means living our life with all challenges, obstacles and problems that come up every day. This is a permanent call of hermeneutics: The call to interpretation and understanding is always a call to transition, to un-covering the primordial tensions in human life between concealment and disclosure, to drawing our attention to the need of exposing ourselves to ourselves and to others in welcoming spirit of hermeneutic hospitality. Facing life means that we realize that very often there is no way to undo the story of our life we cannot identify with. Facing life calls for the recognition of all our experiences without sticking to the negative consequences of our actions and inactions. By letting go of our deepest regrets, we can patiently learn to make peace with ourselves. Being at peace with oneself is not about a passive acceptance of the past, but a conscious recognition of the human condition. It is an expression of the greatness of the wounded self, who does not only welcome and acknowledge the other wounded self, but develops and treasure a relationship with the self by cultivating friendship with the self and the other thus allowing for personal change, growth, and healing. At the heart of hermeneutic hospitality is unconditional welcoming of oneself and another while withholding judgment.

Poetry can aid us in facing life and save us from the destructive power of existential hypocrisy. Being dishonest with oneself might be one of the biggest temptations in life. And to prevent us from deceiving ourselves, poetry makes sure that we do not get accustomed to deception. Therefore, poetry is always full of wisdom of suffering at which we arrive through greatness of our

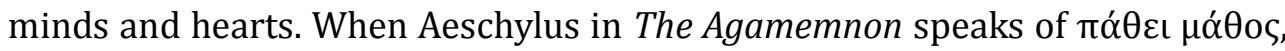
he offers us a legitimate elucidation that wisdom comes from personal suffering. There is no life free from hardship and to be a human being means to willingly accept the whole of life, including the dark or shadow-side of our nature. This acceptance, however, calls for the highest moral sensitivity and responsibility for living our lives. As C.G. Jung reminds us,

it is under all circumstances an advantage to be in full possession of one's personality, otherwise the repressed elements will only crop up as a hindrance elsewhere, not just at some unimportant point, but at the very spot where we are most sensitive. If people 
can be educated to see the shadow-side of their nature clearly, it may be hoped that they will also learn to understand and love their fellow men better. A little less hypocrisy and a little more self-knowledge can only have good results in respect for our neighbor; for we are all too prone to transfer to our fellows the injustice and violence we inflict upon our own natures [Jung 1966, par. 28].

Poetry sensitizes us against hypocrisy and self-deception and empowers us to embrace the whole of personal reality of our immediacy of living. It gives us a lesson of living life; it is a school of character. As in Czesław Miłosz's “A Theological Treatise” [Miłosz 2002]:

\section{At Last To Present}

To present myself at last as an heir to mystical lodges, also as a man different from that of the legend.

Presumably a child of good fortune, who succeeds in everything, I gathered honors from a long, hard-working life.

Really, it happened quite differently from the way it appeared, yet out of pride and shame I abstained from confessions.

In my school years, the brutality of the football field persuaded me

that I was unfit for struggle and I began early to devise an alternative vocation.

Later I experienced real, not imaginary, tragedies, the more difficult to bear because I didn't consider myself entirely innocent.

I learned to bear misfortune the way one bears lameness, though my readers could hardly have guessed it from my writing.

Only a dark tone, an inclination toward a peculiar Manichean strain of Christianity, could have led one to the proper trail.

And, we should add, an entanglement of that individual in the history of the twentieth century, the absurdity of some of his actions, his narrow, miraculous escapes.

As if a substitute vocation had been confirmed, and the Good Lord had asked from me the completion of my oeuvre,

I toiled, I looked for greatness, the failure of which, I thought, could be attributed to the meanness of the era.

Finding greatness in others, sometimes in myself, 
I was grateful for the gift of participation

in an extraordinary divine plan for mortals.

Facing life means to accept oneself unconditionally and with gratitude. We are capable of putting an end to the torment of regret and living our lives to the fullest. Instead of irritating ourselves with what we tried and failed in, we can take delight in thinking about what it is still possible for us to do. We are left to $\mu$ í $\delta \varepsilon \sigma \theta \alpha$, to think, to devise; left in a concentrated state of mind, in serious reflection, which can bring about our healing (the Latin root of the word meditation - meditatio, mederi means "to heal"). It is the complicated simplicity of approaching one's life and the honesty of the direct declarative statement that guide us toward moral identity formation and allows for "a little less hypocrisy and a little more self-knowledge," and thus for "finding greatness in others, sometimes in ourselves." With the poet we can experience a luminous moment of self-acceptance and recognition of the lesson well learned "to bear misfortune the way one bears lameness." However, Miłosz does not elaborate on the way we bear misfortune and lameness, but leaves this existentially and philosophically complex task directly unaddressed. Every human being has to learn to bear oneself and find one's own interpretation of "an extraordinary divine plan for mortals." Poetry's complexity, its refusal of simple rewards or punishments, calls for necessary descent to the level of the individual human experience. Responsibility for our own life means that nobody can give an answer (re-spondeo) to life in lieu of us all on the life journey.

\section{Conclusion: Accepting Our Fragility and Incompleteness}

For Ricoeur, there is no other way to understand oneself except through the interpretation of the expressions of the self through one's actions, symbols, myths, metaphors, and texts. Posing the questions "who acts and suffers?" and "who tells their story of facing life?" discloses the particularities of the narrative recounting of our being and acting. At the very center of Ricoeur's hermeneutic understanding of a person is the conviction that since actions are performed by someone, that someone is always a narrative identity. By telling our individual stories, we uncover our belonging to tradition and culture. As the story told arises from the emplotment of action, the understanding of the person emerges from transforming the plot to the personal identity. This identity is expressed and shaped by narratives, however, this identity is not a stable identity. Following the hermeneutic principle of the mutability of understanding, perceiving a human person as a narrative identity expresses the conviction that what truly matters in life is to encourage a human being to see that we are able to be and act differently (conversio) [Wiercinski 2011]. The fundamental ambiguity of a human person can be understood as primordial openness (Erschlossenheit) to the meaning of our 
perceptions and to self-understanding. This indispensable openness to our self-understanding calls for welcoming and responsible openness for the alterity of the other.

What changes in life are the existential and socio-cultural determinants? However, the imperative to live one's own life to the fullest remains unaltered. We do not have to be fully in control of ourselves. To mature means to learn to accept the fact that not everything is the way we would like to be and that there is nothing wrong with admitting that not everything depends on our choices and decisions. The art of living human life consists in mastering the art of being with oneself and the other. It is the art of facing life. The pivotal task of hermeneutics in disclosing the essence of a human being as an acting and suffering person is, in fact, maximalistic: To assist a person in learning all that is to learn from life and to testify to all that can be testified about the individual and collective human acting and suffering.

Claiming the allegiance to the hermeneutic heritage, we call for humility of the true vision of oneself. Existentially compelling is the fundamental ambivalence of this vision, its mutability and inconsistency. The consent to this inconsistency despite honest attempts to face life as we find it, defiantly and unafraid, is what we are asked for. This indispensable requirement is, at the same time, an encouragement for sovereignty of one's own life's project and a profound desire for learning. It is the matter of taste, a hermeneutic taste: The highest hermeneutic command!

\section{Literature}

Cavafy, C. P. 1992. Collected Poems. Trans. E. Keeley \& Ph. Sherrard. Princeton: Princeton University Press.

Gadamer, H.-G. 2004. Truth and Method. Trans. J. Weinsheimer \& D. G. Marshall. New York: Crossroad.

Hamilton, E. 2013. Entrepreneurship Across Generations: Narrative, Gender and Learning in Family Business. Cheltenham: Edward Elgar Publishing.

Hengel, J. van den. 2002. "Naming the Unspeakable". In: Wiercinski, A. (ed.) Between the Human and the Divine: Philosophical and Theological Hermeneutics. Toronto: The Hermeneutic Press.

Jonas, H. 1984. The Imperative of Responsibility: In Search of an Ethics for the Technological Age. Trans. H. Jonas \& D. Herr. Chicago: University of Chicago Press.

Jung, C. G. 1966. "Two Essays on Analytical Psychology”. In: Jung, C. G. Collected Works. Vol. 7. Princeton: Princeton University Press.

Malraux, A. 1933. La Condition humaine. Paris: Gallimard.

Miłosz, Cz. 1988a. "Esse”. Trans. Cz. Miłosz \& R. Pinsky. In: Miłosz, Cz. Collected Poems. New York: The Ecco Press. 
Miłosz, Cz. 1988b. “No More”. Trans. A. Miłosz. In: Miłosz, Cz. Collected Poems. New York: The Ecco Press.

Miłosz, Cz. 2002. "A Theological Treatise". Trans. Cz. Miłosz \& R. Hass. Spiritus: A Journal of Christian Spirituality Vol. 2 no. 2: 193-204.

Ricoeur, P. 1984. Time and Narrative. Vol. 1. Trans. K. McLaughlin, D. Pellauer. Chicago \& London: The University of Chicago Press.

Ricoeur, P. 1988. Time and Narrative. Vol. 3. Trans. K. Blamey, D. Pellauer. Chicago \& London: The University of Chicago Press.

Ricoeur, P. 1992. Oneself as Another. Trans. K. Blamey. Chicago: University of Chicago Press.

Ricoeur, P. 2002. "Life in Quest of Narrative". In: Wood, D. (ed.) On Paul Ricoeur: Narrative and Interpretation. London: Taylor \& Francis.

Ricoeur, P. 2004. Memory, History, Forgetting. Trans. K. Blamey \& D. Pellauer. Chicago: University of Chicago Press.

Wiercinski, A. 2003. Between Suspicion and Sympathy: Paul Ricoeur's Unstable Equilibrium. Toronto: The Hermeneutic Press.

Wiercinski, A. 2011. "The Primacy of Conversation in Philosophical Hermeneutics". In:, Wiercinski, A. (ed.) Gadamer's Hermeneutics and the Art of Conversation. Münster: LIT Verlag. 


\title{
Andrew Wiercinski (University of Freiburg)
}

\section{Hermeneutic Notion of a Human Being as an Acting and Suffering Person: Thinking with Paul Ricoeur}

\begin{abstract}
Acting and suffering subjectivity makes a grand sujet in Ricoeur's philosophy. In his Time and Narrative Ricoeur created the notion of narrative identity which is an individual internalized and evolving life strory. The narrative alone might define the "who". Whoever lives and exists, suffers. Ricoeur metaphorically defined life as a cloth. We can add, Wiercinski continues, that this cloth is woven with pain. It is pain which makes the cloth, and, at the same time, it is also a joy of the human condition. As humans, we are called to wear this cloth as well as to understand what does it mean - from the hermeneutic perspective.
\end{abstract}

Keywords: narrative identity, life story, pain, joy, Ricoeur

Ethics in Progress (ISSN 2084-9257). Vol. 4 (2013). No. 2. pp. 18-33. 